\title{
Neutron source plans face uncertain future
}

Washington. The US Department of Energy (DOE) has asked a top-level advisory committee to reassess the future needs of US researchers for access to neutron sources, following the cancellation earlier this year of the proposed \$3-billion Advanced Neutron Source (ANS).

But a letter sent last month by Martha Krebs, director of the Office of Energy Research, requesting the advice of the DoE's Basic Energy Sciences Advisory Committee (BESAC), sets no deadline for a response.

Furthermore, say officials at DoE laboratories, the cash-strapped department is in no rush to fill the gap left by the cancellation of the ANS. They add that, as a result, neutron users may have to wait ten years or more before a new neutron source comes on line.

Neutrons are increasingly in demand from condensed-matter physicists, materials scientists, structural biologists and others studying the structure of molecules. Scientists in all these disciplines are able to use both the steady stream of neutrons generated by reactors and the short bursts created by proton accelerators through a process known as spallation - generation of neutrons by the acceleration of protons into a heavy metal target - for carrying out different types of experiment.

Furthermore, neutron science is one of the few capital-intensive research fields in which the United States seriously lags behind Europe. According to a BESAC report published in 1993, Europe has three times as many neutron scientists as the United States - and, since 1970, has spent five times as much money on neutron facilities.

The 1993 report was prepared by a subpanel of the advisory committee chaired by Walter Kohn of the University of California at Santa Barbara. It concluded that the energy department should give priority to the construction of the ANS reactor, and then back a new 1-MW spallation source.

But BESAC now faces the task of sorting the debris left by the cancellation of the ANS into a coherent neutron programme for the department.

In her letter, Krebs asks BESAC chairman Carl Lineberger, professor of chemistry at the University of Colorado at Boulder, to evaluate possible upgrades of existing reactor-based neutron sources at the Oak Ridge National Laboratory (ORNL) in Tennessee, and the Brookhaven National Laboratory on Long Island, New York. She also asks the panel for its advice on the type of accelerator-based neutron source that could be built at ORNL for "about one-third" of the estimated \$3-billion cost of the ANS.

Oak Ridge, which was to have hosted the ANS, has already been identified by the DOE as its preferred site for a new spallation source - even though it has no design in hand. The laboratory is due to receive $\$ 8$ million in the next financial year, which starts in October, to draw one up. It also has an ageing reactor source, the High-Flux Isotope Reactor (HFIR), which will require major refurbishment to extend its useful life.

By contrast, the Argonne National Laboratory in Illinois has a well-advanced design

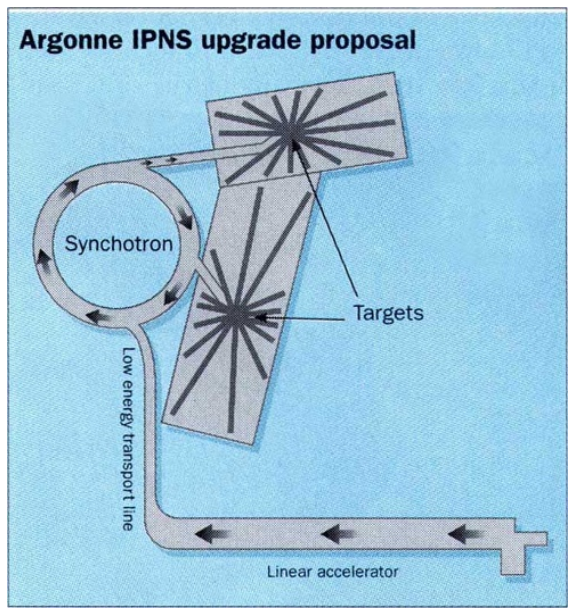

for a 1-MW spallation source, which it would like to build as an upgrade to its existing Intense Pulsed Neutron Source (IPNS). This would cost around $\$ 750$ million - $\$ 175$ million less than elsewhere because it would be able to make use of existing buildings, according to Bruce Brown, director of IPNS.

Brookhaven also has a design for a spallation source. But its top priority is a longoverdue, \$30-million instrumentation upgrade for its 30-year-old High Flux Beam Reactor. Like HFIR, this reactor's pressure vessel will need replacing in the near future.

And the Los Alamos National Laboratory in New Mexico is proposing a new target for its existing neutron scattering centre, arguing that this could provide the United States with an internationally competitive neutron spallation source three years from now for less than $\$ 100$ million.

Given these different demands, some difficult choices will have to be made. "I don't think there is \$1 billion out there for a community of 1,500 people," says Roger Pynn of the Los Alamos Neutron Scattering Experiment. "If BESAC has any sense of realism, they are going to recommend doing something with existing facilities."

But Krebs's request to BESAC - as well as the department's immediate budget plans - implies that a new spallation source will eventually be built at Oak Ridge. Except that the embattled department has no money, and not much enthusiasm to proceed. If everything goes to plan, says Iran Thomas, acting director of the DOE's Office of Basic Energy Research, the source could be producing neutrons by 2002 . But, he says, that completion date is "wildly optimistic".

Colin Macilwain

\section{HIV scandal hits Bombay blood centre}

New Delhi. A blood bank in Bombay operated by the India Red Cross Society (IRCS) has been closed down following a government decision to conduct an inquiry into charges that the centre had supplied blood infected with HIV to hospitals in the city between 1992 and 1994.

The medical officer in charge of the blood bank has already been removed from his post, and more officials are expected to lose their jobs. The affair has caused concern throughout India, as the IRCS is intended to set national standards for blood safety.

The Bombay blood bank, which supplies 15,000 units of blood a year - about onethird of the city's requirements - is one of the 16 blood-testing centres making up the National AIDS Control Organization (NACO), set up in the region with an US\$87-million grant from the World Bank.

Eight out of 30 children suffering from thalassaemia who are registered with the blood bank have become HIV-positive, and the Maharashtra state government has told its health officials to track down all known recipients of the tainted blood.

The affair came to light when $J$. $N$. Banarjee, chairman of the IRCS subcom- mittee on blood transfusion services, examined the records of the blood bank. These showed that HIV-positive blood had been supplied to at least 10 city hospitals, including one that specializes in transfusion services.

In addition, there have been suspicions that employees of the blood bank, rather than discarding infected blood, have been selling it on the black market created by an overall shortage of blood supplies.

India has more than a thousand blood banks, half of them run privately. But these generate only 1.95 million units a year - less than half the country's need. An expert committee has estimated that India needs a further investment of about US\$90 million to upgrade its blood banks to acceptable levels of hygiene.

According to NACO, the control of AIDS in India will be difficult to achieve if blood supplies are not made safe. Out of 1,108 cases of AIDS reported up to 1 June, it estimates that 11.1 per cent had contracted the disease from infected blood.

NACO also claims that 30 per cent of blood is collected from professional donors, many of whom are HIV-positive.

K. S. Jayaraman 